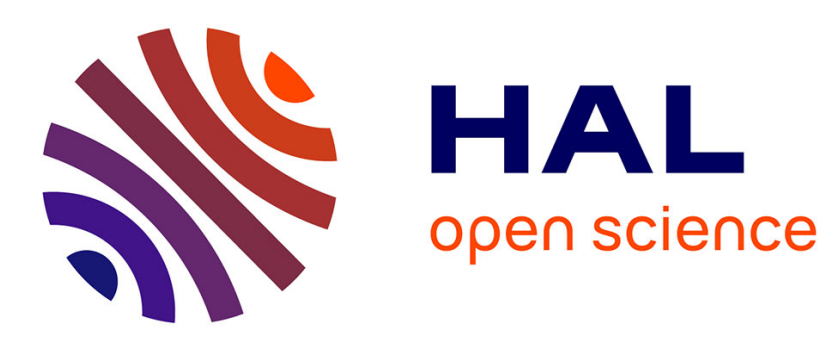

\title{
Mesoporous silica thin films for molecular sieving and electrode surface protection against biofouling
}

Maria Bueno Serrano, Christelle Despas, Grégoire Herzog, Alain Walcarius

\section{To cite this version:}

Maria Bueno Serrano, Christelle Despas, Grégoire Herzog, Alain Walcarius. Mesoporous silica thin films for molecular sieving and electrode surface protection against biofouling. Electrochemistry Communications, 2015, 52, pp.34-36. 10.1016/j.elecom.2015.01.010 . hal-01504773

\section{HAL Id: hal-01504773 \\ https://hal.univ-lorraine.fr/hal-01504773}

Submitted on 26 Jun 2019

HAL is a multi-disciplinary open access archive for the deposit and dissemination of scientific research documents, whether they are published or not. The documents may come from teaching and research institutions in France or abroad, or from public or private research centers.
L'archive ouverte pluridisciplinaire HAL, est destinée au dépôt et à la diffusion de documents scientifiques de niveau recherche, publiés ou non, émanant des établissements d'enseignement et de recherche français ou étrangers, des laboratoires publics ou privés. 


\title{
Mesoporous silica thin films for molecular sieving and electrode surface protection against biofouling
}

\author{
Maria Bueno Serrano, Christelle Despas, Grégoire Herzog,* Alain Walcarius \\ Laboratoire de Chimie Physique et Microbiologie pour l'Environnement (LCPME), UMR 7564, \\ CNRS - Université de Lorraine, 405 rue de Vandœuvre, 54600 Villers-lès-Nancy, France. \\ *Corresponding author: gregoire.herzog@univ-lorraine.fr
}

This document is a postprint. Final version has been published in Electrochemistry Communications, 2015, 52, 34-36 (https://doi.org/10.1016/j.elecom.2015.01.010).

\begin{abstract}
Electrode fouling is a major challenge for the long term use of sensors in real samples as it leads to the decay of the electroanalytical signal and is often caused by the formation of an inhibiting layer formed by biomolecules. We demonstrate here that ordered and vertically aligned mesoporous silica generated at the surface of an indium tin oxide electrode by electrochemically assisted self-assembly act as a molecular sieve and a protective layer for the electrode surface. They indeed prevent the adsorption of size excluded large undesired molecules (e.g. haemoglobin) while allowing the detection of small redox active molecules likely to reach the electrode surface through the film (e.g. propranolol) with almost no loss of sensitivity. At a bare electrode, the oxidation of propranolol is completely inhibited in the presence of $5 \mu \mathrm{M}$ haemoglobin. At a modified electrode, the sensitivity for propranolol in the absence of haemoglobin is $(72.8 \pm 2.9) \mathrm{mA} \mathrm{mol}^{-1}\left(R^{2}=0.992, N=7\right)$ and it remains similar in the presence of $5 \mu \mathrm{M}$ haemoglobin with a value of $(67.4 \pm 7.2) \mathrm{mA} \mathrm{mol}^{-1}\left(R^{2}=0.992, N=7\right)$.
\end{abstract}

Keywords: biofouling, electro-assisted self-assembly, mesoporous silica film, propranolol, haemoglobin adsorption 


\section{Introduction}

The detection of pollutants in real media without sample preparation remains very challenging to the analytical chemist [1]. Fouling and non-specific adsorption on sensor surfaces hinders the deployment of accurate and sensitive sensors for long-term environmental and biomedical monitoring [2]. Indeed; the prolonged use of sensors in real samples for an extended period of time generally results in the formation of an unwanted layer of biomolecules. This fouling often results in the decay of the sensor performance and eventually its failure [3]. A number of strategies were developed in recent years to prevent the fouling of electrochemical sensors [4,5]. Chemical modification of the electrode with molecular monolayers may prevent macromolecules adsorption and hence surface fouling [6,7]. Electrode surface was also modified physically by electrodeposited nanoporous gold [8], which dimensions $(<50 \mathrm{~nm})$ minimised the fouling effect of bovine serum albumin. Although effective for the exclusion of large proteins, nanoporous gold might be ineffective against the fouling of smaller proteins (e.g. cytochrome $\mathrm{c}$ and haemoglobin). In recent years, mesoporous silica thin films with pore diameter lower than $10 \mathrm{~nm}$ have been developed for electroanalytical, electrocatalytic and other electrochemical applications [9]. MCM-41 and SBA-15 mesoporous silica have been used as molecular sieves $[10,11]$ in the past but never to protect an electrode surface. Mesoporous silica thin films obtained electrochemically with a surfactant template present a high level of order with pores orientation normal to the electrode surface, a feature which improves significantly mass transfer $[12,13]$. We suggest here their use as a protective surface layer based on the sieving properties at the nanoscale. Indeed, the diameter of pores obtained by electrochemically assisted self-assembly is around 2-3 nm [14], which is large enough to allow diffusion of small redox-active species and at the same time small enough to prevent diffusion of proteins. As a small organic redox-active molecule, we have selected propranolol, a $\beta$-blocker often used in the treatment of hypertension and which can be detected electrochemically [15-17]. As a surface-fouling agent, we have used haemoglobin, whose dimensions are larger than the pore diameter [18]. The electrochemical behaviour of propranolol at bare ITO and at ITO modified with mesoporous silica thin film was investigated. The influence of the presence of haemoglobin on the propranolol oxidation signal was also assessed.

\section{Material and Methods}

\subsection{Chemicals}

Tetraethoxysilane (TEOS, 98\%, Alfa Aesar), ethanol (95-96\%, Merck), $\mathrm{NaNO}_{3}$ (99\%, Fluka), $\mathrm{HCl}$ (Riedel de Haen, $1 \mathrm{M}$ solution) and cetyltrimethylammonium bromide (CTAB, 99\%, Acros) were used for film synthesis. Ruthenium hexamine chloride $\left(\mathrm{Ru}\left(\mathrm{NH}_{3}\right)_{6}{ }^{3+}, 98 \%\right.$, Aldrich), $\mathrm{NaCl}$ (98\%, Prolabo), $\mathrm{Na}_{2} \mathrm{HPO}_{4}$ (99\%, Prolabo) and propranolol hydrochloride (99\%, Sigma) and haemoglobin from bovine blood and bovine serum albumin (lyophilized powder, Sigma-Aldrich) were used for film permeability 
studies and analytical characterisation. All solutions were prepared with high purity water (18.2 $\mathrm{M} \Omega$ $\mathrm{cm}^{-1}$ ) obtained from a Purelab Option-Q from ELGA.

\subsection{Electrochemically assisted self-assembly of mesoporous silica thin films}

Mesoporous silica thin films were prepared by electrochemically assisted self-assembly [12]. A sol was prepared daily as follows: ethanol and $0.1 \mathrm{M} \mathrm{NaNO}_{3}$ aqueous solution were mixed in a 1:1 v/v ratio. TEOS and CTAB were added to the mixture to reach $100 \mathrm{mM}$ TEOS and $32 \mathrm{mM}$ CTAB concentrations. After setting the $\mathrm{pH}$ at 3 by addition of $\mathrm{HCl}$, the sol was hydrolysed under stirring for 2.5 hours at room temperature. The sol was then ready to be used as the electrodeposition medium. Indium tin oxide (ITO) plates (surface resistivity, 8-12 $\Omega$, from Delta Technologies) were modified by applying, for $30 \mathrm{~s}$, a potential of $-1.3 \mathrm{~V}$ versus a silver wire acting as a pseudo-reference electrode. A stainless steel plate was used as a counter electrode. The ITO plates were then rinsed thoroughly with ultrapure water and left overnight at $130^{\circ} \mathrm{C}$ to ensure a good cross-linking of the silica network. The surfactant template was removed by immersion in a stirred ethanol solution containing $0.1 \mathrm{M} \mathrm{HCl}$ for $15 \mathrm{~min}$.

\subsection{Cyclic voltammetry experiments}

All electrochemical experiments were done with a PGSTAT12 (film formation) from Ecochemie (Metrohm, Switzerland) or on an EMStat2 potentiostat (film characterisation and propranolol detection) from Palmsens (Netherlands). A stainless steel rod was used as a counter electrode and the reference electrode was $\mathrm{Ag}|\mathrm{AgCl}| 1 \mathrm{M} \mathrm{KCl}$ (Metrohm, Switzerland). Modified electrodes were characterised by cyclic voltammetry at $100 \mathrm{mV} \mathrm{s}^{-1}$ in a de-aerated solution of $5 \mathrm{mM} \mathrm{Ru}\left(\mathrm{NH}_{3}\right)_{6}{ }^{3+}$ in 0.1 $\mathrm{M} \mathrm{NaNO}_{3}$ to assess the defect-free quality of the mesoporous silica thin films. Films presenting defects before surfactant extraction were discarded. Cyclic voltammetry of propranolol was done at $100 \mathrm{mV} \mathrm{s}^{-1}$ in a $0.1 \mathrm{M}$ phosphate buffer ( $\mathrm{pH} \mathrm{5)}$ either in the absence or the presence of $5 \mu \mathrm{M}$ haemoglobin, which was used as a model protein inhibiting the detection of propranolol.

\section{Results and Discussion}

Propranolol was oxidised irreversibly at a bare ITO electrode at $+1.29 \mathrm{~V}$ (Figure 1). The peak observed was due to the oxidation of the hydroxyl group to a ketone group, involving two protons and two electrons [19]. The presence of the mesoporous silica thin film on the electrode surface shifted the oxidation potential of propranolol to $+1.47 \mathrm{~V}$ and the oxidation peak current decreased by $13 \%$. Despite a slightly hindered diffusion of propranolol through the mesoporous silica thin film, the electrode surface remained available to propranolol oxidation allowing its detection. The electrochemistry of $\mathrm{Hb}$ was investigated at a bare electrode and at a modified electrode (Inset of 
Figure 1). The absence of $\mathrm{Hb}$ reduction at the modified electrode confirmed that the protein could not reach the electrode surface to react and that its size prevented from entering the pores.

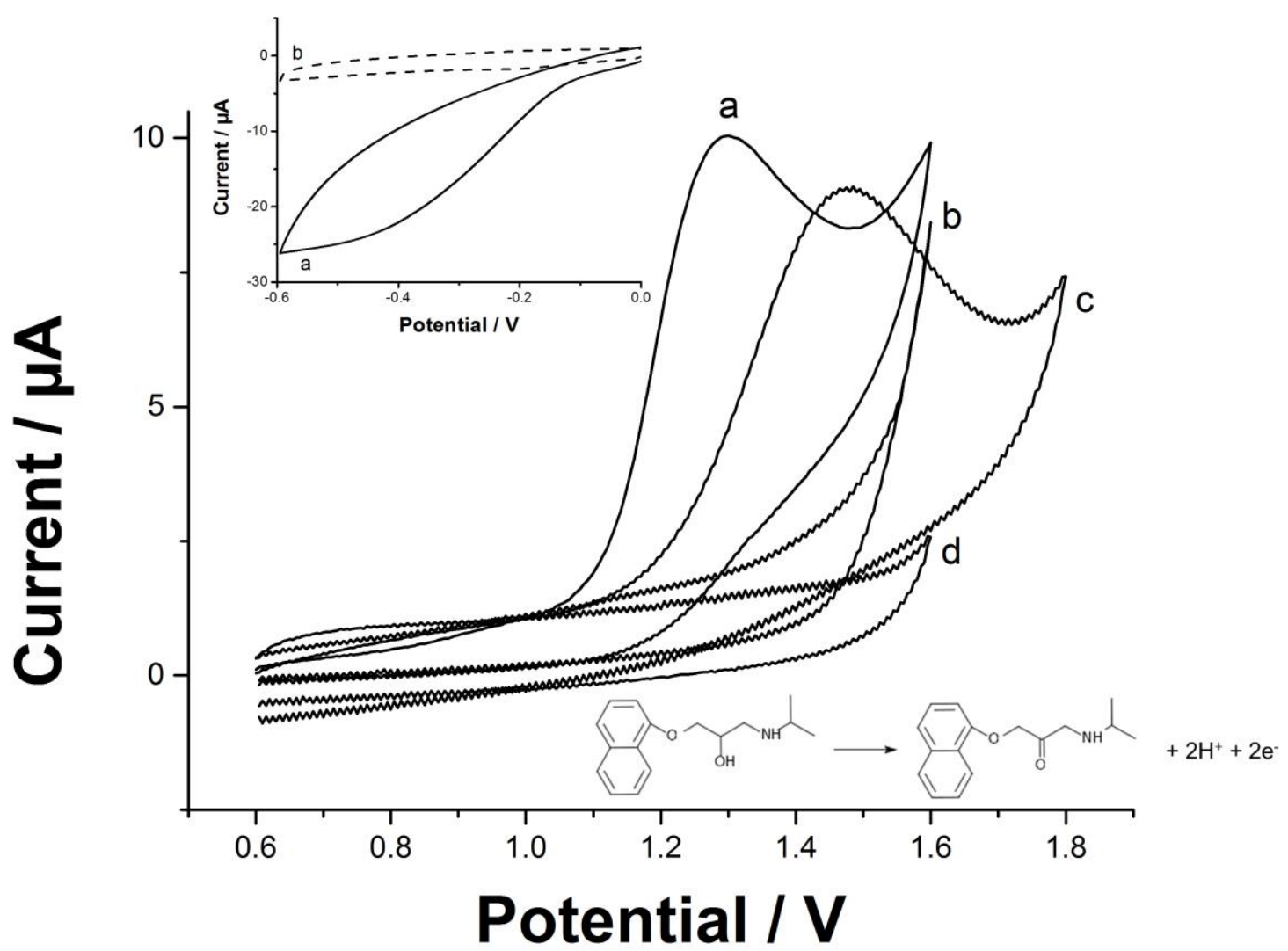

Figure 1: Cyclic voltammograms in the presence of $100 \mu \mathrm{M}$ propranolol at (a) a bare electrode and at (b) a modified electrode. Blanks at both bare (c) and modified (d) electrodes are also shown. Inset: Inset: Cyclic voltammetry of $\mathrm{Hb}$ at a (a) bare ITO electrode and at a (b) modified electrode.

The oxidation of propranolol in the presence of bovine serum albumin was also investigated at both bare and modified electrodes. At an electrode modified with a mesoporous silica thin film, the signal for propranolol oxidation was not recorded, although it was observed at a bare electrode. Previous studies have shown that albumin and propranolol interact [20]. Propranolol is detected at a bare electrode, which suggests that albumin adsorbs at the electrode surface and bound propranolol can be oxidized at the electrode surface (data not shown). At a modified electrode, no propranolol is detected as albumin might be kept away from the surface by the mesoporous silica thin film (data not shown). In their studies, Collins et al. demonstrated that albumin adsorbed at the liquid-liquid interface but did not inhibit the propranolol signal due to drug-protein interaction [20]. Oxidation of $100 \mu \mathrm{M}$ propranolol was then investigated in the presence of $5 \mu \mathrm{M}$ haemoglobin at both bare and modified ITO electrodes (Figure 2). At a bare electrode, the oxidation signal for propranolol was not observed, hindered by the adsorption of haemoglobin proteins at the surface of the electrode. It is interesting to note that the fouling of the electrode surface occurred at a concentration as low as $5 \mu \mathrm{M}$. When a 
mesoporous silica thin film was formed on the electrode surface, the oxidation signal of propranolol at $+1.41 \mathrm{~V}$ was not hindered by the presence of haemoglobin. The peak current was measured at $(7.71 \pm 0.48) \mu \mathrm{A}$. This value was slightly lower than the oxidation peak current of $(8.09 \pm 0.29) \mu \mathrm{A}$ measured for $100 \mu \mathrm{M}$ propranolol at a modified ITO electrode in the absence of haemoglobin. The oriented silica film enabled the detection of propranolol in the presence of haemoglobin, which was not possible at a bare ITO electrode. The propranolol response should come from diffusion through the pores rather than from eventual defects in the films as demonstrated by the absence of any signal for a redox probe in solution (i.e. $\mathrm{Ru}\left(\mathrm{NH}_{3}\right)_{6}{ }^{3+}$ ) before surface extraction. Hence, the homogeneity of the mesoporous silica film needed to be demonstrated (Inset of Figure 2). After template removal, the film became porous to the redox probe as it was shown by the large peak current of $\mathrm{Ru}\left(\mathrm{NH}_{3}\right)_{6}{ }^{3+}$. This indicates that the only access to the electrode surface was through the pores of around $3 \mathrm{~nm}$ in diameter $[12,13]$.

Small organic molecules (e.g. propranolol) can reach the electrode surface while larger proteins (e.g. haemoglobin with the estimated hydrodynamic diameter of $6.4 \mathrm{~nm}$ [18]). are kept away, the mesoporous silica thin film acting as protective layer. Mesoporous silica with larger pores (prepared from Brij56 and Pluronic 123 templates) could accommodate medium size proteins such as myoglobin or cytochrome $c$ while they blocked the transport of the larger bovine serum albumin [21].

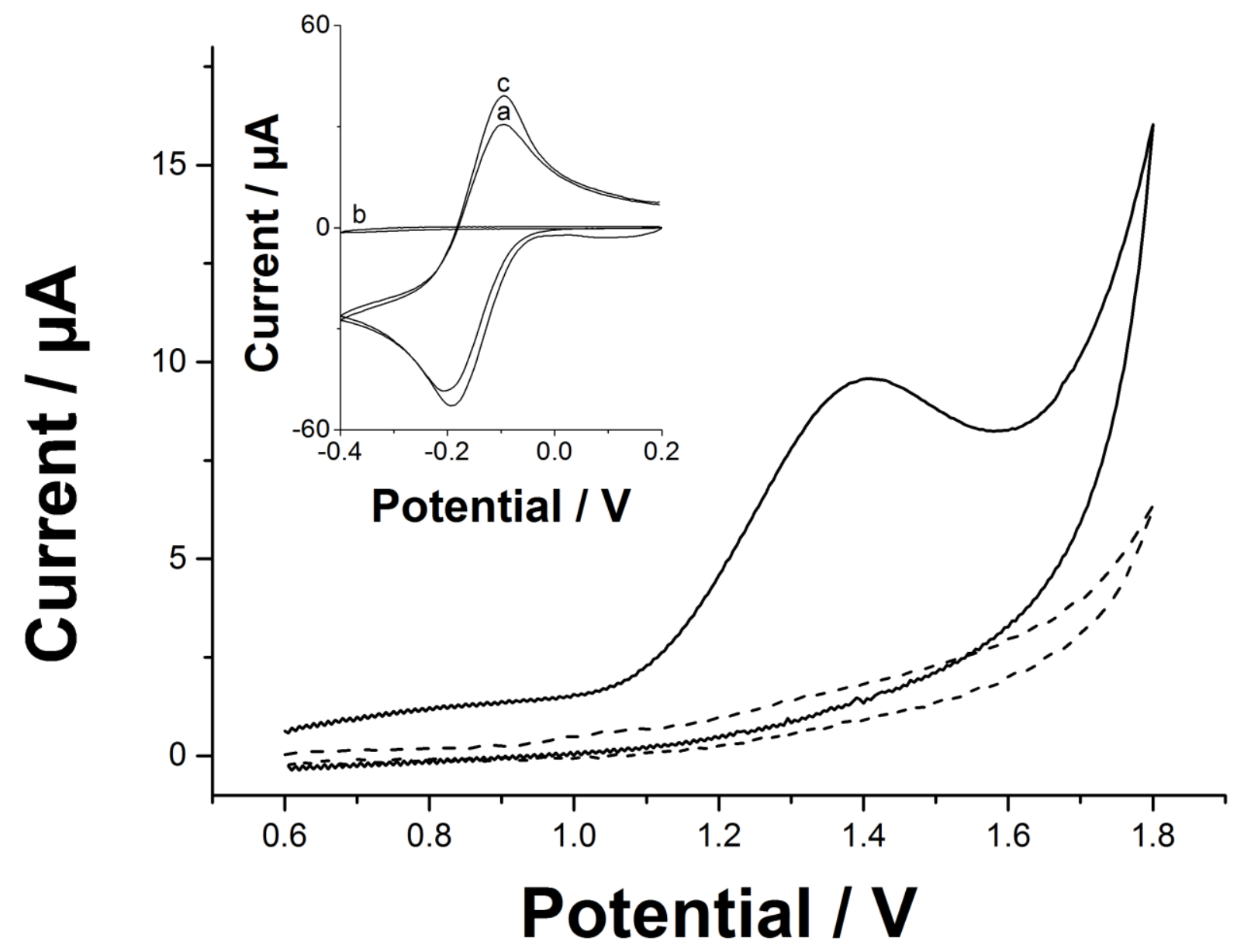


Figure 2: Cyclic voltammograms of $100 \mu \mathrm{M}$ propranolol in the presence of $5 \mu \mathrm{M}$ Haemoglobin at a bare ITO electrode (dashed curve) and at an ITO electrode modified with mesoporous silica thin film (solid line). Inset: Cyclic voltammograms of $5 \mathrm{mM}$ Ruthenium hexamine at a bare ITO electrode (a), an ITO modified electrode (b) before and (c) after extraction of surfactant.

Calibration curves were built for propranolol concentrations ranging from 5 to $100 \mu \mathrm{M}$ at both bare and modified ITO electrodes in the absence and in the presence of haemoglobin (Figure 3). In the absence of haemoglobin, the oxidation peak current increased linearly with the propranolol concentration with approximately the same sensitivity at both bare and modified electrodes. The presence of $5 \mu \mathrm{M}$ haemoglobin in the solution did not disturb significantly the detection of propranolol at the modified ITO electrode since a sensitivity of $(67.4 \pm 7.2) \mathrm{mA} \mathrm{mol}^{-1}\left(R^{2}=0.992, N=7\right)$ was obtained (compared to a $(72.8 \bullet 2.9) \mathrm{mA} \mathrm{mol}^{-1}\left(R^{2}=0.992, N=7\right)$ in the absence of haemoglobin), whereas it totally inhibited the propranolol response at bare ITO. The lowest concentration detected was $5 \mu \mathrm{M}$ propranolol. A detection limit of this order was expected for simple cyclic voltammetry experiments and it could be improved by the use of square wave or differential pulse voltammetries [16]. These results suggest that electrodes covered with a mesoporous silica thin film could be used for the detection of small organic molecules in fouling media.

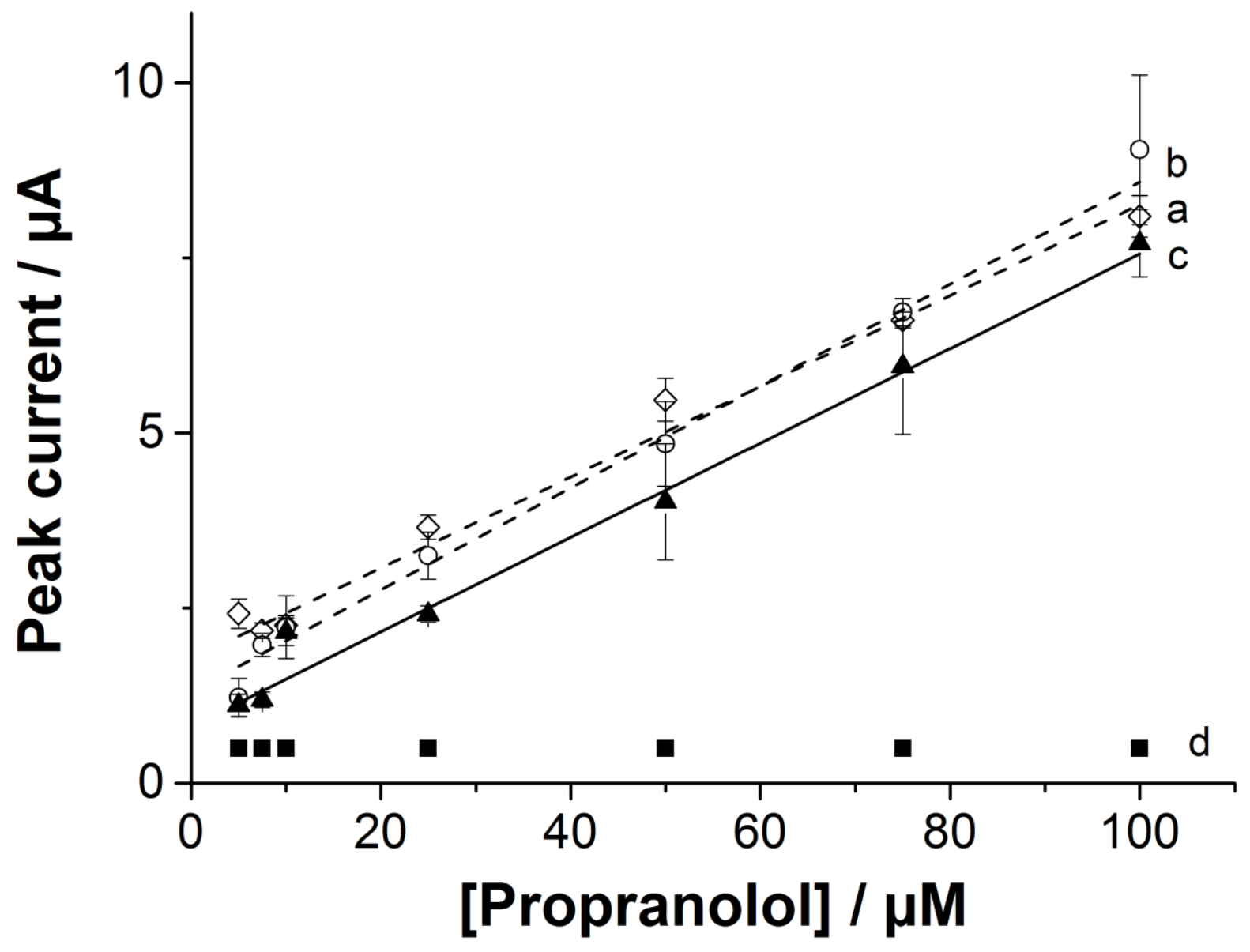


Figure 3: Calibration curves for propranolol $(5-100 \mu M)$ in the absence $(a, b)$ and in the presence $(c, d)$ of $5 \mu M$ haemoglobin at bare $(a, d)$ and modified $(b, c)$ ITO electrodes. $v=100 \mathrm{mV} \mathrm{s} s^{-1}$ in phosphate buffer (pH 5). Each experiment was done in triplicate.

\section{Conclusions}

We have demonstrated that the electrogeneration of well-ordered and oriented mesoporous silica thin films is very promising for electrode surface protection. Propranolol is detected at the modified electrode in the presence of haemoglobin with a similar sensitivity to the one in the absence of haemoglobin. Protein dimensions are larger than the silica mesopore diameter and cannot diffuse to the electrode surface and foul it. The surface of the modified electrode has therefore remained active for the detection of propranolol in the presence of haemoglobin, while the bare electrode has become inoperative under the same conditions. Unfortunately, the protection was not as effective in the presence of albumin.

\section{Acknowledgements}

The authors acknowledge Ms Mohana Afsharian for preliminary experiments.

\section{References}

[1] R. Byrne, D. Diamond, Nat. Mater. 5 (2006) 421.

[2] C.M.A. Brett, L. Angnes, H.-D. Liess, Electroanalysis 13 (2001) 765.

[3] B. O’Flynn, F. Regan, A. Lawlor, J. Wallace, J. Torres, C. O’Mathuna, Meas. Sci. Technol. 21 (2010) 124004.

[4] C. Blaszykowski, S. Sheikh, M. Thompson, Chem. Soc. Rev. 41 (2012) 5599.

[5] A. Barfidokht, J.J. Gooding, Electroanalysis 26 (2014) 1182.

[6] G. Herzog, D.W.M. Arrigan, Anal. Chem. 75 (2003) 319.

[7] A.L. Gui, E. Luais, J.R. Peterson, J.J. Gooding, ACS Appl. Mater.\& Interf. 5 (2013) 4827.

[8] J. Patel, L. Radhakrishnan, B. Zhao, B. Uppalapati, R.C. Daniels, K.R. Ward, M.M. Collinson, Anal. Chem. 85 (2013) 11610.

[9] A. Walcarius, Chem. Soc. Rev. 42 (2013) 4098. 
[10] J. M. Kisler, A. Dähler, G. W. Stevens, A. J. O’Connor, Microporous Mesoporous Mater. 4445 (2001) 769.

[11] Y. Liu, Q. Xu, X. Feng, J.-J. Zhu, W. Hou, Anal. Bioanal. Chem. 387 (2007) 1553.

[12] A. Walcarius, E. Sibottier, M. Etienne, J. Ghanbaja, Nat. Mater. 6 (2007) 602.

[13] A. Goux, M. Etienne, E. Aubert, C. Lecomte, J. Ghanbaja, A. Walcarius, Chem. Mater. 21 (2009) 731.

[14] M. Etienne, Y. Guillemin, D. Grosso, A. Walcarius, Anal. Bioanal. Chem. 405 (2013) 1497.

[15] C.J. Collins, D.W.M. Arrigan, Anal. Chem. 81 (2009) 2344.

[16] S.X. Dos Santos, É.T.G. Cavalheiro, C.M.A. Brett, Electroanalysis 22 (2010) 2776.

[17] I. Baranowska, M. Koper, J. Braz. Chem. Soc. 22 (2011) 1601.

[18] D. Arosio, H.E. Kwansa, H. Gering, G. Piszczek, E. Bucci, Biopolymers 63 (2002) 1.

[19] E. Bishop, W. Hussein, Analyst 109 (1984) 65.

[20] C.J. Collins, C. Lyons, J. Strutwolf, D.W.M. Arrigan, Talanta 80 (2010) 1993.

[21] Y. Yamauchi, T. Kimura, Chem. Commun. (2013) 11424. 